\title{
UVB effects on a plankton community: results from a large-scale enclosure assay
}

\author{
Isabelle Laurion $^{1, *}$, David R. S. Lean ${ }^{2}$, Warwick F. Vincent ${ }^{1}$ \\ ${ }^{1}$ Département de Biologie \& Centre d'études nordiques, Université Laval, Ste-Foy, Québec G1K 7P4, Canada \\ ${ }^{2}$ Department of Biology, University of Ottawa, Box 450, Station A, Ottawa K1N 6N5, Canada
}

\begin{abstract}
The long-term effects of natural and enhanced ultraviolet-B (UVB) exposure on picocyanobacteria, size-fractionated chlorophyll a (chl a), primary production (photosynthesis-irradiance parameters) and grazing activity on phytoplankton were investigated over a $20 \mathrm{~d}$ period in a mesotrophic lake in central Ontario, Canada. Large volume enclosures (20000 1) open to the sediments were installed in the littoral zone and sampled at $6 \mathrm{~d}$ intervals. Four radiation treatments were run: UVB-screened giving $0 \%$ incident UVB, natural ambient (100\% UVB), and 2 lamp-enhanced treatments giving $112 \%$ biologically weighted UVB (range of 109 to $126 \%$ depending on cloud cover) and $118 \%$ biologically weighted UVB (114 to $138 \%)$. The light utilization efficiency of the phytoplankton $(\alpha)$ decreased under enhanced UVB, but there was no significant decrease in biomass (chl a or cell counts). Populations of the nanoflagellate Ochromonas sp. significantly increased under enhanced UVB; after $20 d$ the cell concentration of this species was ca 3.6 times higher relative to the natural UVB control. However, differences between treatments in picocyanobacteria, $<2 \mu \mathrm{m} \mathrm{chl} a$, other nanoplanktonic groups, maximum photosynthetic rates, sensitivity to photoinhibition and grazing activity were generally small relative to the variability between duplicate enclosures. These results indicate a low impact of natural and increased levels of incident UVB on the inshore plankton community in this type of lake environment.
\end{abstract}

KEY WORDS: Ultraviolet-B · Photosynthesis . Phytoplankton Enclosure . Temperate lake Ochromonas Grazing - Mixotroph

\section{INTRODUCTION}

Although many studies have shown that ambient ultraviolet-B (UVB) radiation can have deleterious effects on phytoplankton (Karentz et al. 1994, El-Sayed et al. 1996, and references therein), most of the evidence to date has been derived from short-term assays of photosynthesis (e.g. Cullen et al. 1992, Behrenfeld et al. 1993, Holm-Hansen et al. 1993). Some longer-term experiments have examined algal growth responses, although mostly on marine communities (Jokiel \& York 1984, Davidson et al. 1994, Wängberg et al. 1996, Keller et al. $1997 \mathrm{a}$, b). Phototrophic organisms have a variety of protection and repair mechanisms against

- Present address: Institute of Zoology and Limnology, University of Innsbruck, Technikerstr. 25, A-6020 Innsbruck, Austria. E-mail: isabelle.laurion@uibk.ac.at
UVB damage (Vincent \& Roy 1993), and longer-term assays allow the natural induction of such mechanisms, the selection of UV-tolerant species, and the adjustment of trophic-level interactions. For example, Bothwell et al. (1993) found that short-term exposure to UVB resulted in depressed growth of periphytic algae, but that this initial inhibitory effect was reversed after 3 to $4 \mathrm{wk}$, ultimately resulting in a higher biomass community with a distinct species composition.

Temperate lakes contain higher concentrations of UV-screening compounds (chromophoric dissolved organic matter, CDOM) than the sea and are therefore relatively protected against UV effects on phytoplankton photosynthesis and growth. However, freshwater communities might be susceptible to sudden increases in UVB exposure (Williamson 1995, Xiong et al. 1996), particularly if they are acclimated to low average ultraviolet radiation (UVR) fluxes (Helbling et al. 1992, 
Neale et al. 1997). A significant rise in ground-level UVB radiation has been reported in the north temperate zone (Kerr \& McElroy 1993). Moreover, temperate lakes may be subject to changes in spectral UVR attenuation in the water column as a consequence of changing CDOM concentrations caused by climate change and lake acidification (Schindler et al. 1996a). Thermal regime and mixing depth are also influenced by radiative transfer through the water column and can be affected by changes in CDOM (Schindler et al. 1996b). All of these factors are likely to influence UVB dose and dosage rate (Cullen \& Lesser 1991) and the magnitude of direct (e.g. impairment of photosystem II) and indirect effects (e.g. production of reactive oxygen species) in aquatic ecosystems.

Phytoplankton species vary widely in their response to UVB exposure (Worrest et al. 1981, Jokiel \& York 1984, Karentz et al. 1991, Wängberg et al. 1996). Thus, many authors have suggested that changes in the UVB regime will lead to changes in the structure and composition of the aquatic community towards the most adapted species. A change in community composition at the base of the aquatic food web will alter predation, diversity and trophic dynamics (Häder \& Worrest 1991). The need to evaluate these long-term impacts of enhanced UVB has been emphasized (e.g. Häder et al. 1995, Williamson 1995) but only a few studies to date have examined the magnitude of such effects in multispecies or multi-trophic-level communities. Previous ecosystem-level experiments have generally employed small-volume or shallow-water assay systems, e.g. $1 \mathrm{l}$ Chemglass vessels, Helbling et al. (1992); $1 \mathrm{~cm}$ deep river-flumes, Bothwell et al. (1994); $500 \mathrm{ml}$ polythene bags, Davidson et al. (1996); 201 Cubitainers, Bergeron \& Vincent (1997). More recently, Keller et al. (1997a, b) studied the effect of enhanced UVB radiation on marine trophic levels of a coastal ecosystem using large enclosures $(13000$ l). They found a reduced phytoplankton biomass during the second week of sampling under the UVB-enhanced treatments, followed by a reduction of the copepod nauplii abundance (Keller et al. 1997a). However, despite the 10 -fold increase in biologically damaging UVB, these effects did not persist throughout the experiment, nor were they translated into effects at higher trophic levels. In a study on phytoplankton from a clear lake in the Austrian Alps, the community seemed to be well adapted to the high UVB radiation characteristic of high altitude (Halac et al. 1997), as there were no significant differences in species composition during 16 days under ambient and shielded UVB in $1 \mathrm{~m}^{3}$ enclosures

In the present study we addressed the question of community responses to UVB by way of a replicated enclosure experiment using a large-volume assay sys- tem. We simulated an increase in UVB irradiance with 2 different sets of UVB lamps, and observed the response of the photosynthetic community during 20 days relative to natural and shielded UVB conditions. In order to evaluate how UVB might affect different production and loss processes in the community, we measured the biomass of different planktonic components, the physiological state of phytoplankton by way of photosynthetic assays, and the zooplankton grazing activity.

\section{MATERIALS AND METHODS}

Study site and enclosures. The study was conducted in Jack's Lake, a mesotrophic lake in central Ontario, Canada $\left(43^{\circ} 70^{\prime} \mathrm{N}, 78^{\circ} 02^{\prime} \mathrm{W}\right)$. The watershed of the lake is forested, with seasonal dwellings along most shorelines. The lake is composed of several basins of different morphometry that are separated from one another by shallow channels.

The enclosures were designed to hold a water column in the nearshore part of the lake while allowing natural exchanges with the overlying atmosphere and the littoral sediments. They were constructed of a woven black polyethylene (Fabrine-Dupont) resistant to UV degradation and were left to soak offshore for $4 \mathrm{~d}$ prior to installation. The enclosures were cylindrical in shape, $5 \mathrm{~m}$ in diameter and open at both ends. They were anchored by way of chains that were sewn into the base of the side skirts and were deployed over the littoral zone where it sloped from ca 0.75 to $1.25 \mathrm{~m}$. This gave an average depth of $1 \mathrm{~m}$ and a total volume in each enclosure of ca $20000 \mathrm{l}$. A flotation collar of polyurethane foam extended $10 \mathrm{~cm}$ from the water surface and held the columns upright.

The enclosures were installed and left in place for $2 \mathrm{~d}$ to settle before the experiment started. They were sampled every 6 to $10 \mathrm{~d}$ from May 10 to June 23, 1995. Lakewater was collected in the morning with a $50 \mathrm{~cm}$ long Van Dorn bottle which sampled the depth stratum from 25 to $75 \mathrm{~cm}$ below the surface. A small addition of nutrients was made to the enclosures each week $(2 \%$ of total $\mathrm{P} \mathrm{d}^{-1}=1.7 \mathrm{mg} \mathrm{P} \mathrm{m}^{-3} \mathrm{wk}^{-1} ; 22 \mathrm{mg} \mathrm{NO} \mathrm{N}_{3}-\mathrm{N} \mathrm{m}^{-3}$ $w^{-1}$ ) to counter the effect of removing the advective exchange of nutrients with the rest of the lake. On June 4, heavy rainfall caused the lake water level to rise, and for some of the enclosures this caused a lifting of the curtain from the sediments on the downslope side. This resulted in a rapid exchange between the outside and inner water masses, obscuring any differences that were earlier established. The effect of this flood can be seen from changes in the chlorophyll $a$ (chl a) biomass (see below). Hence, for most of the results reported below, we restrict our analyses to the 
sampling dates prior to the flood (May 10, 16, 22, and 29).

Radiation treatments. The experiment was designed with 4 replicated treatments: ambient sunlight $(100 \%$ UVB), UV-shielded by covering the surface of the enclosure with Mylar-D sheets $10 \%$ UVB; this treatment was not duplicated until May 30), and UVBenhanced with 2 different supplemental UVB irradiances from fluorescent bulbs (UVB1 and UVB2). The lake was also sampled concurrently to determine whether large discrepancies occurred between the enclosures and external water. Enhancement of UVB was obtained with fluorescent lamps (National Biological Corporation, model FS20T12/UVB) turned on, starting from May 11 , for $4 \mathrm{~h}$ each day, from 11:00 to 15:00 h, to coincide with the daily period of highest solar UVB flux. The experimental UVB was not adjusted for changes in cloud cover, which alter the amount of ambient UVB. Calculations with incident ambient spectra showed that ca $60 \%$ of the total daily UVB flux was received at the lake surface during this period of the day. We avoided using the lamps at other times of day to prevent extreme UVB and UVB:PAR exposures (PAR: photosynthetically available radiation, 400 to $700 \mathrm{~nm}$ ). Lamps were covered by cellulose acetate to remove UVC from the spectrum (wavelengths $<280 \mathrm{~nm}$ ); the resultant UV spectrum is given in Fig. 1. The 2 UVB treatments were obtained by placing 4 bulbs on a wooden cross at $70 \mathrm{~cm}$ (UVB1) and $40 \mathrm{~cm}$ (UVB2) from the water surface.

The bulb installation had a negligible shading effect on PAR but we were unable to achieve fully homogeneous distribution of enhanced UVB across the large surface area of each enclosures. The UVB irradiance provided by the 2 sets of lamps varied from almost zero at the edge of the enclosures to 0.46 and $0.84 \mathrm{~W} \mathrm{~m}^{-2}$ at the water interface directly under the lamps. On a cloudy day, the unweighted UVB flux immediately below the bulbs could rise to $50 \%$ above ambient, but averaging 25 measurements at the water surface from transects across the enclosures gave values of 0.18 and $0.23 \mathrm{~W} \mathrm{~m}^{-2}$, equivalent to a mean unweighted flux of 105 and $107 \%$ of mean ambient UVB (estimated as $50 \mathrm{~kJ} \mathrm{~m}^{-2} \mathrm{~d}^{-1}$ ). Weighting these measured flux values for their biological effect provides a more realistic estimate of the UVB exposure. For these calculations we applied the UV response curve from Cullen et al. (1992) for UVR photoinhibition of a marine diatom, setting the weighting factor to 1.0 at $300 \mathrm{~nm}$. The resultant biologically weighted exposures were 3.3 and $6.6 \mathrm{~kJ} \mathrm{~m}^{-2} \mathrm{~d}^{-1}$ below the lamps at the water surface. These values averaged across the enclosures are equivalent to mean enhancements of 12 and $18 \%$ of the weighted ambient values (estimated as 5 to $14 \mathrm{~kJ} \mathrm{~m}^{-2}$ $\mathrm{d}^{-1}$ ), with ranges from 9 to 26 and 14 to $38 \%$ depend-

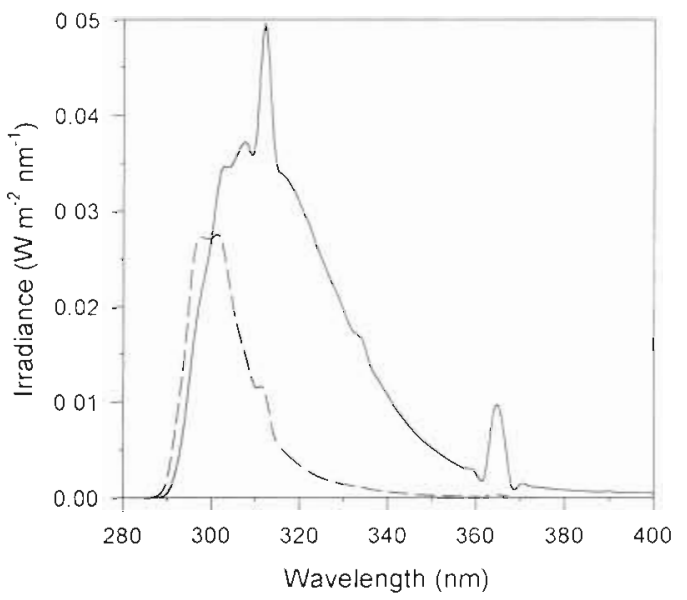

Fig. 1 Spectral emission of FS20T12/UVB fluorescent lamps at $40 \mathrm{~cm}$ distance. The absolute data were obtained using an Optronics OL 752 spectroradiometer. Curves are presented with (dashed line) and without (solid line) biological weighting using a curve for UV inhibition of photosynthesis

ing on day-to-day variations in cloud cover and stratospheric ozone conditions during the experiment.

Physical measurements. The lamp and sun spectra were obtained with an Optronics OL 752 spectroradiometer. The instrument was set to take irradiance measurements every $2 \mathrm{~nm}$ from 250 to $800 \mathrm{~nm}$. The light sensor is a submersible PTFE-coated integrating sphere cosine receptor. The spatial patterns of downwelling UVB irradiance at the water surface under the lamps were measured with a Goldilux hand-held UVB meter from Oriel, equipped with a model 70221 probe. Values were highly correlated with those obtained using the Optronics. The daily variations in incident UVB during the course of the experiment were approximated from measurements by the single monochromator Brewer instrument (Kerr et al. 1985) located in Toronto, $180 \mathrm{~km}$ SW from Jack's Lake. Profiles of solar radiation were obtained with a Biospherical PUV-500 radiometer; this instrument provides a measure of downwelling irradiance at $305,320,340$ and $380 \mathrm{~nm}$ (full bandwidth at half maximum is 8 to $10 \mathrm{~nm}$ ) and of downwelling PAR. Fine structure temperature profiles were obtained with the same instrument. A coupled transmissometer (10 cm pathlength, Sea Tech) gave profiles of transmittance at $660 \mathrm{~nm}$.

Phytoplankton enumeration. For picacyanobacteria counts, $125 \mathrm{ml}$ of water was preserved with paraformaldehyde (final concentration of $0.5 \%$ ). For nanoplankton counts and identification (cells of 2 to $20 \mu \mathrm{m}), 250 \mathrm{ml}$ was preserved with a solution of glutaraldehyde/paraformaldehyde (final concentration of $1 \% / 0.1 \%$ ). Counts and identification were performed with a Zeiss Axiovert 10 inverted epifluorescence microscope, equipped with a Plan-Neofluor $100 \times / 1.30$ 
objective. A fluorescent stain (DAPI) was added to the counting chamber to locate the nanoplanktonic cells and Nomarski lighting enabled us to identify cells as in Lovejoy et al. (1993). Counts and identification of nanoplanktonic species were performed at each sampling date in 4 of the 8 enclosures (no replicates) and in the lake. This allowed us to examine changes in planktonic composition and diversity.

Chlorophyll a. Subsamples of water $(100 \mathrm{ml})$ from each enclosure were filtered onto MFS glass fiber filters (Micro Filtration System; equivalent to GF/F filters). Additional $100 \mathrm{ml}$ samples were prefiltered through $2 \mu \mathrm{m}$ Nuclepore filters and then onto MFS filters to obtain the picoplanktonic fraction. Chl a was then extracted with boiling $90 \%(\mathrm{v} / \mathrm{v}$ ) ethanol (Nusch 1980 ) and the fluorescence of the extract was measured with a Sequola Turner Model 450 fluorometer equipped with NB440 (blue excitation) and SC665 (red emission) filters. Readings were calibrated with chl a from Anacystis nidulans (Sigma Biochemical Co.) in an ethanol solution that was measured by spectrophotometry according to Nusch (1980). This solution was diluted to 8 concentrations to generate a calibration curve for the fluorometer. Phaeopigments were corrected for by acidification.

Photosynthesis. The effects of UVB on the physiological state of the phytoplankton community were evaluated by way of photosynthesis versus irradiance $(P-E)$ curves. Subsamples from each enclosure were incubated in $23 \mathrm{ml}$ glass vials under 8 PAR irradiances $(92$, $48,25,12,6,1.6,0.8$ and $0.2 \%$ of ambient PAR) without UVR. Neutral density filters were used to produce the PAR gradient (combination of filter nos, 130, 209, 210 and 211, Lee Filters). These filters cut all UVB and partly UVA (cut-off wavelength at $340 \mathrm{~nm}$, except for the clear filter used for $92 \%$ PAR, where cut-off was at $325 \mathrm{~nm})$. Two additional vials for each enclosure were incubated in the dark to correct for passive uptake of ${ }^{14} \mathrm{C}$. Enclosures were sampled in the morning and the vials were incubated for $2 \mathrm{~h}$ at $5 \mathrm{~cm}$ under the lake surface, with ${ }^{14} \mathrm{C}_{-} \mathrm{HCO}_{3}{ }^{-}$at a final concentration of $270 \mathrm{nCi} \mathrm{ml}^{-1}\left(10^{4} \mathrm{~Bq} \mathrm{ml} \mathrm{m}^{-1}\right)$. After incubation, the vials were stored in the dark and cold until filtration of the total vial content onto MFS filters. All filters were kept frozen until counting. They were subsequently placed in scintillation vials and fumed for approximately $20 \mathrm{~h}$ with $0.1 \mathrm{ml}$ of $1 \mathrm{~N} \mathrm{HCl}$. Scintillation cocktail was added and the samples then counted in a Beckman LS 6500 scintillation counter. Each vial was run through 2 cycles to check that all chemiluminescence had dissipated The data were then fitted by non-linear regression to the photosynthesis-irradiance equation of Platt et al. (1980) to obtain estimates of $\alpha$ (ascending slope at limiting irradiances) and $P_{\mathrm{m}}$ (light-saturated photosynthetic rate). As a simple index of photoinhibition during the
${ }^{14} \mathrm{C}$-incubation, we calculated the parameter $R_{\beta}$, the percent reduction of photosynthesis at $1000 \mu \mathrm{mol}$ photons $\mathrm{m}^{-2} \mathrm{~s}^{-1}$ relative to $P_{\mathrm{m}}$. For this calculation we used the equation of Platt et al. (1980) and the parameters obtained for each P-E curve. Dissolved inorganic carbon was measured at each sampling date with Hg-preserved samples in a Shimadzu Total Carbon analyzer.

Zooplankton grazing. The phytoplankton loss rates due to zooplankton grazing were evaluated with the dilution method (Landry \& Hassett 1982) on May 11, 17 and 23 in each of the enclosures. Four dilution mixtures $(1: 0,3: 1,1: 1,1: 3$ unfiltered to filtered water) were incubated for $24 \mathrm{~h}$ in clear polystyrene bottles (with polyethylene caps; cut-off wavelength at $300 \mathrm{~nm}$ ). No nutrients were added to the bottles. The apparent growth rates of phytoplankton were calculated by measuring the chl $a$ in the $<2$ and $>2 \mu$ m fractions at the beginning and end of the incubation. Counts of picocyanobacteria were also performed. Instantaneous coefficients of phytoplankton growth $(k)$ and microzooplankton grazing $(g)$ were determined from leastsquares and linear regression analysis of the relationship between the rate of change of chlorophyll (or picocyanobacteria) and the fraction of unfiltered water in the various bottles.

\section{RESULTS}

\section{Physical environment}

Jack's Lake had a DOC concentration of ca $6 \mathrm{mg} \mathrm{l}^{-1}$, which conferred a moderately high level of UV-screening protection on the aquatic community (Fig. 2). Underwater PAR and UVR were measured on 5 dates during the experiment but there was no significant change through time. For the date closest to the midpoint of the experiment (May 20), the $1 \%$ of incident UVB at $320 \mathrm{~nm}$ was found at about $60 \mathrm{~cm}$; the diffuse attenuation coefficients $\left(K_{d}\right)$ at 320,340 and $380 \mathrm{~nm}$ were $7.3,5.0$ and $2.6 \mathrm{~m}^{-1}$, respectively. The photic zone exceeded the mixed layer during summer stratification $\left(K_{\mathrm{d}}\right.$ for PAR $=0.47 \mathrm{~m}^{-1} ; 1 \%$ PAR at $\left.9.8 \mathrm{~m}\right)$, and transmittance at $660 \mathrm{~nm}$ in the epilimnion was equal to $80 \%$. These optical conditions are typical for lakes in this temperate, mixed hardwood-conifer region of Canada.

A seasonal thermocline was established by the end of May, with the metalimnion extending from 6 to $11 \mathrm{~m}$ depth. Except on very windy days, diurnal stratification was a feature of the surface waters (typically in the first 1 to $2 \mathrm{~m}$ ), trapping the planktonic cells in the upper water column. Fig. 3 shows the establishment of a diurnal thermocline through the course of a sunny 


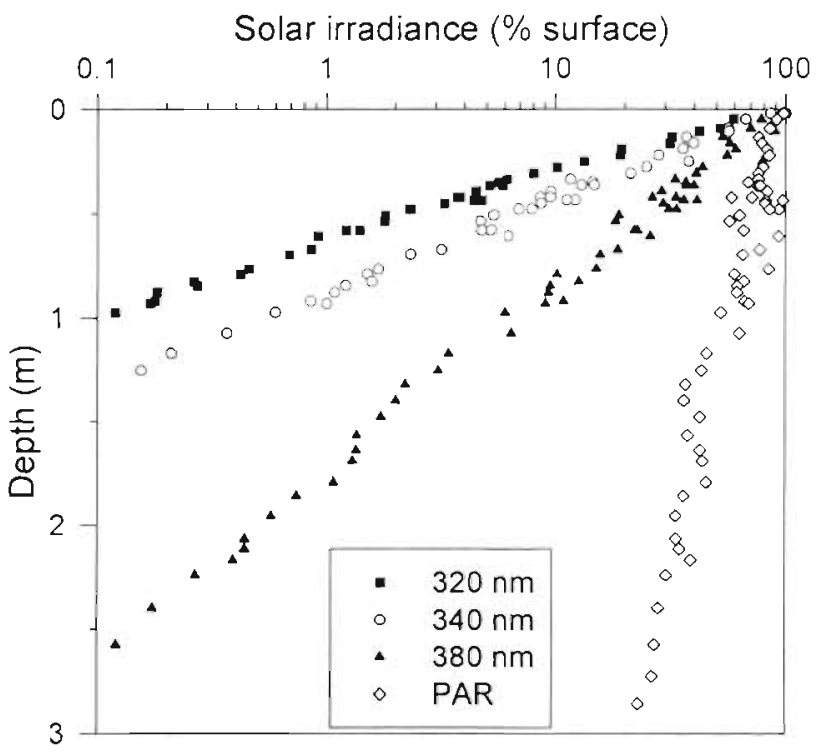

Fig. 2. Depth profiles of UV radiation at 320,340 and $380 \mathrm{~nm}$ and of PAR (400 to $700 \mathrm{~nm}$ ) in Jack's Lake, May 20, 1995

day, with formation in the morning and disruption by increased wind-induced mixing during the afternoon. Surface water temperature in the lake varied from 11 to $15^{\circ} \mathrm{C}$ during the experiment. Comparative measurements of temperature were made inside each enclosure and also in the surrounding lakewater on May 26, near the end of the sampling period. Surface water temperatures in the enclosures were 0.7 to $2.6^{\circ} \mathrm{C}$ above those in the lake, and at $1 \mathrm{~m}$ depth were 0.6 to $1.6^{\circ} \mathrm{C}$ above the equivalent lake measurements. The trend of near-surface warming was observed in both environments, to a slightly greater extent in the enclosures (up to a $1^{\circ} \mathrm{C} \mathrm{m}^{-1}$ greater temperature gradient in the enclosures).

\section{Chlorophyll a}

Jack's Lake has mesotrophic levels of chl a, from 2 to $4.5 \mathrm{\mu g} \mathrm{l}^{-1}$ during the summer sampling period in 1995. Lake chl a was maximal at the beginning of the experiment, and decreased to $2 \mu \mathrm{g}^{-1}$ by the end of May. Picophytoplankton $(<2 \mu \mathrm{m}$ fraction) contributed on average $30 \%$ of the total chl a biomass.

Overall, the trends through time in the enclosures were similar to those observed in the lake, with a general decline in $>2 \mu \mathrm{m}$ chl a (Fig. $4 \mathrm{~b}$ ) and therefore a gradual increase in the proportional abundance of the smaller fraction. These similarities between the lake and enclosures indicate that there was no significant enrichment effect of the nutrient additions to the enclosures. Repeated-measure analysis of variance was performed on the data set for each variable measured over the period May 10 to 29, with subsequent analysis of least significant differences as in Hochberg \& Tamhane (1987). During this assay period, the average contribution of picoplanktonic chl $a$ in the enclosures increased from 24 to $43 \%(\mathrm{p}=0.0011)$. This fraction was significantly higher when UVB was shielded, compared to the enhanced UVB treatments ( $\mathrm{df}=4,3$, $F=9.07, \mathrm{p}=0.0503$ ), but this was mainly caused by differences in the larger cell fraction. There were no significant differences in the absolute values of chl a in the $<2 \mu \mathrm{m}$ fraction $(\mathrm{df}=4,3, F=1.55, \mathrm{p}=0.3752$; Fig. 4a).

Chl $a$ in the phytoplankton cells larger than $2 \mu \mathrm{m}$ showed significant differences between treatments (df $=4,3, F=52.42, p=0.0042$ ). There were also significant changes through time ( $p=0.0012)$ but the changes were parallel for all treatments, i.e. the differences between treatments at the start of the experiment were maintained as the community evolved through time. Both UVB-enhanced treatments contained higher concentrations of chl a than the Ambient and Mylar treatments, and UVB2 contained higher concentrations of chl a than UVB1 (Fig. 4 b).

\section{Phytoplankton community}

The total abundance of picocyanobacteria in the lake increased from 14 to $51 \times 10^{3}$ cells $\mathrm{ml}^{-1}$ over the period of the experiment. The analysis of variance showed no significant differences between treatments in picocyanobacteria biomass ( $\mathrm{df}=4,3, F=1.59, \mathrm{p}=0.3665$; averaged values given in Table 1), which closely

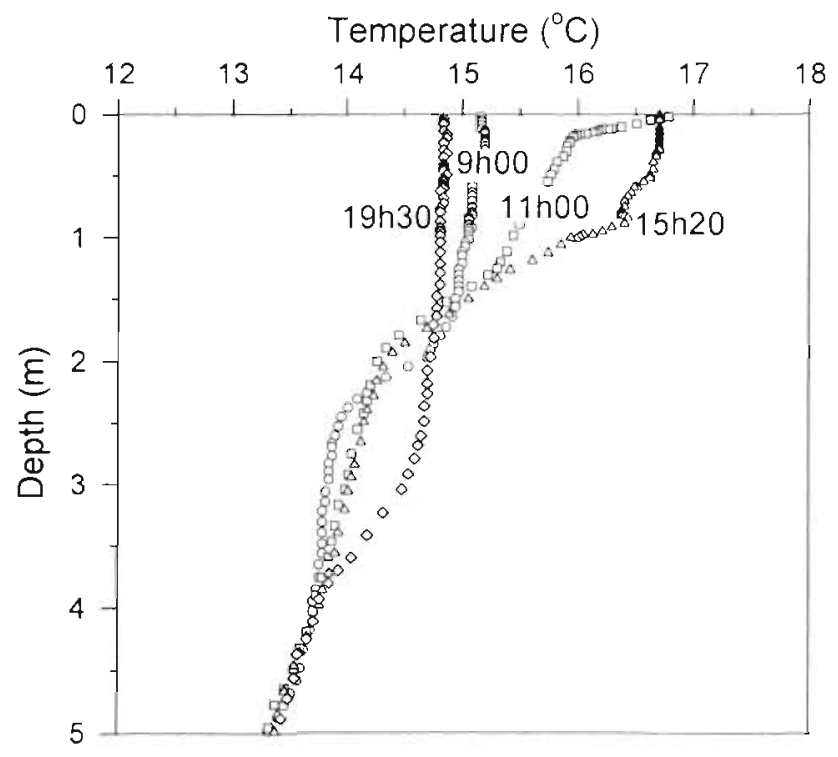

Fig. 3. Diurnal stratification and mixing in Jack's Lake on a date of clear skies and high solar insolation (May 26, 1995) 

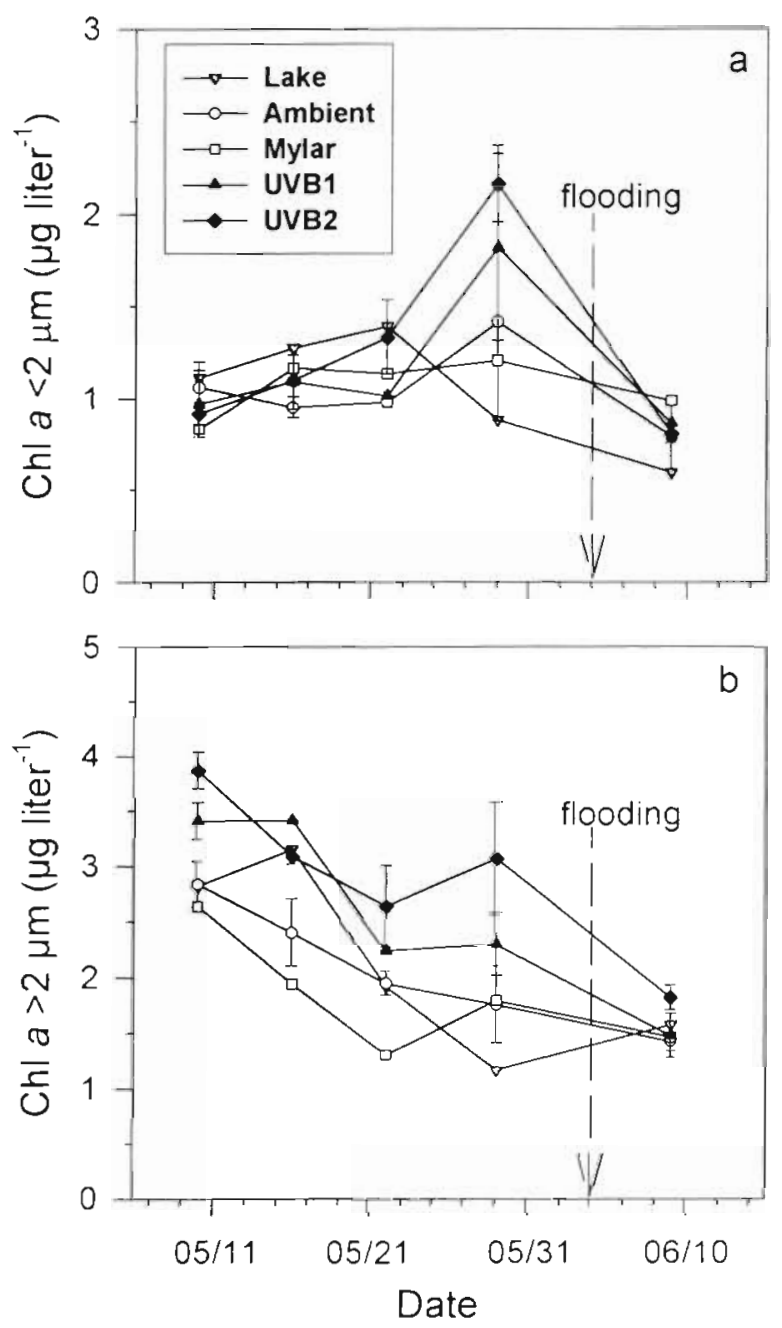

Fig. 4. Chl a concentrations through time in each UVB treatment and in the lake. Error bars represent \pm 1 SE for duplicates. The Mylar treatment had no replicate in this part of the experiment. (a) $<2 \mu \mathrm{m}$ chl $a$, (b) $>2 \mu \mathrm{m}$ chl $a$

tracked the population trends in the external lakewater through time.

Microscopic observations of the microbial community were performed to examine differences between treatments in cell composition, abundance of dominant species and diversity. Analysis of variance could not be done on these unduplicated counts, however there were no clear differences or trends among treatments in the total abundance of nanoplanktonic cells, the importance of individual size classes, or the Shannon diversity index (average of $2.1, \mathrm{CV}=12 \%$ ). The averaged abundance of nanoplanktonic cells (all treatments pooled) is given in Table 1 However, one of the pigmented nanoflagellates, a ca $11 \times 6 \mu \mathrm{m}$ Ochromonas sp., was highly responsive to the enhanced UVB regime (Fig. 5). For the period prior to flooding, the concentration of Ochromonas sp. was on average

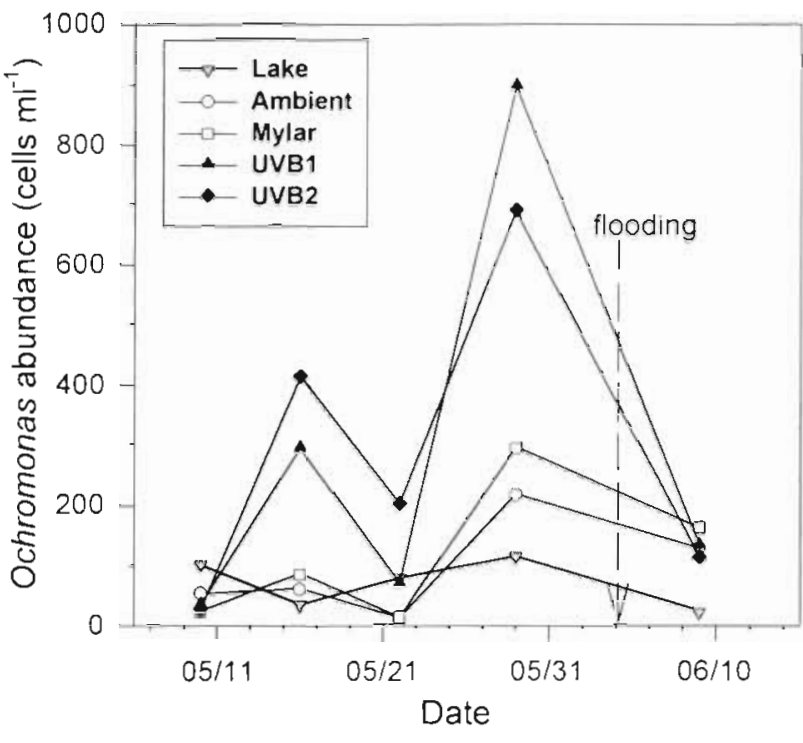

Fig. 5. Ochromonas sp. abundance through time in each UVB treatment and in the lake

328 cells $\mathrm{ml}^{-1}$ in the UVB-enhanced treatments, compared to 84 and 103 cells $\mathrm{ml}^{-1}$ in the Ambient and Mylar treatments. We applied a repeated-measure ANOVA to these data by pooling the 2 UVB treatments and comparing these with the lake and other treatments. This analysis showed a significant UVB effect ( $\mathrm{df}=3,1, F=1095.00, \mathrm{p}=0.0222$ ). Ochromonas sp. varied from almost absent to $16 \%$ of the total count for nanoplanktonic cells in the enclosures under enhanced UVB and remained at or below 100 cells $\mathrm{ml}^{-1}$ in the lake.

\section{Photosynthesis}

The photosynthesis-irradiance equation of Platt et al. (1.980) gave an excellent fit to our data, with an average $\mathrm{r}^{2}$ of 0.97 (range $=0.918$ to 0.996 ). The standard error of $P_{\mathrm{m}}$ estimates averaged $6 \%$ of absolute values and ranged between 2 and $11 \%$. There was a significant treatment effect ( df $=3,3, F=9.23, p=0.0503$ ) on the initial slope of the $P-E$ curve $(\alpha)$ superimposed on the trend of decreasing $\alpha$ through time in all enclosures $(p=0.0001$; Fig. 6a). There were significant differences between the ambient UVB and UVB2 treatments, and between the Mylar treatment and both UVB enhancements. Mylar had the highest $\alpha$, followed by ambient, UVB1 and UVB2 $(0.0128,0.0116,0.0112$, and $0.0104 \mu \mathrm{g} \mathrm{C} \mu \mathrm{g} \mathrm{chl} \mathrm{a}^{-1} \mathrm{~h}^{-1}$ [ $\mu \mathrm{mol}$ photons $\left.\mathrm{m}^{-2} \mathrm{~s}^{-1}\right]^{-1}$. respectively). No significant differences were found between treatments for either $P_{\mathrm{m}}(\mathrm{df}=3,3, F=1.55, \mathrm{p}=$ 0.3643 ; Fig. $6 \mathrm{~b}$ ) or $R_{\beta}$ (df $=3,3, F=2.53, \mathrm{p}=0.2327$ ). $R_{\beta}$ averaged $76 \%$ at the beginning of the experiment (all 
treatments pooled), diminished to 45 and $11 \%$ on May 16 and 22, respectively, and increased again to $43 \%$ on May 29.

\section{Grazing}

Instantaneous coefficients for phytoplankton growth $(k)$ and microzooplankton grazing $(g)$ were calculated for total chl a, picoplanktonic chl $a$ and picocyanobacteria (Table 1). The repeated measure ANOVA showed no significant differences between treatments for either parameter $(p>0.5)$. However, there was a significant increase $(p<0.05)$ through time of the grazing rate as measured with total chl $a$ and picocyanobacteria.

\section{DISCUSSION}

Over the course of this long-term experiment we observed a significant effect of UVB on the $P$ versus $E$ relationship of phytoplankton, specifically on the slope of the light-limited portion of the curve. This physiological or community-level effect is the integrated response by the whole community to changes in light conditions, but is likely to be of relatively minor importance in the shallow, well-illuminated waters which characterize the inshore littoral zone. This effect was not translated into a significant net change in phytoplankton community biomass, growth rates or grazing losses. There was some indication of changing species composition; for example the mixotrophic species Ochromonas sp. significantly increased under UVB (cell concentration after 20 d was 3.6 times higher), perhaps reflecting an increase in photochemical liberation of organic nutrients for osmotrophy or phagotrophy via bacterial production (Wetzel 1993, Lindell et al. 1995). The results of Halac et al. (1997) also show positive responses by some phytoplankton species (e.g. Cyclotella sp., Chlamydomonas sp.) to changes in UVA + PAR, but not to UVB. There was no evidence in our study of collapse of specific populations in response to increased UVB exposure, nor of any large scale taxonomic shift in the Mylar enclosures screened from UVB.

It is possible that the large variability between replicates masked more subtle community-level responses to UVB. The logistic constraints of our large scale experiment (and those conducted elswhere; e.g. Keller et al. $1997 b$ ) precluded the use of many replicates and thereby limited the statistical power of our experimental design. High variability is a typical feature of large enclosure experiments in general (e.g. Halac et al. 1997, Keller et al. 1997b). For example, the coefficient of variation for picocyanobacteria abundance in our duplicated enclosures averaged $25 \%$, but could be as high as $70 \%$. Moreover, the coefficient of variation between treatments at the starting date (May 10) was already high for several algal species counted $(\mathrm{CV}=$ $30 \%)$. This reflects the natural heterogeneity of the littoral zone when the enclosures were installed. Also, the chl $a$ of cells larger than $2 \mu$ m showed significant differences between treatments. These differences cannot be ascribed to a UVB effect because these differences were already present at the beginning of the experiment and were simply maintained as spring progressed. The persistence of these differences, however, confirms that the enclosures were relatively well sealed from the external lake environment throughout the first $3 \mathrm{wk}$ of the experiment.

The percentage of chl a in the picophytoplankton fraction was significantly higher when UVB was shielded compared to the enhanced UVB treatments. However, this difference was small (37 versus $30 \%$ of total chl a) and was mainly caused by differences in the larger fraction. This latter effect cannot be explained by differential grazing on the larger fraction under UVB since our grazing assays showed no significant treatment effects. These grazing estimates are useful for a comparison between treatments, but should be viewed with caution in absolute terms because the bottles were not enriched with nutrients (Landry \& Hassett 1982). Also, the nutritional status of algal cells is known to influence their response to UVB, and nutri- 

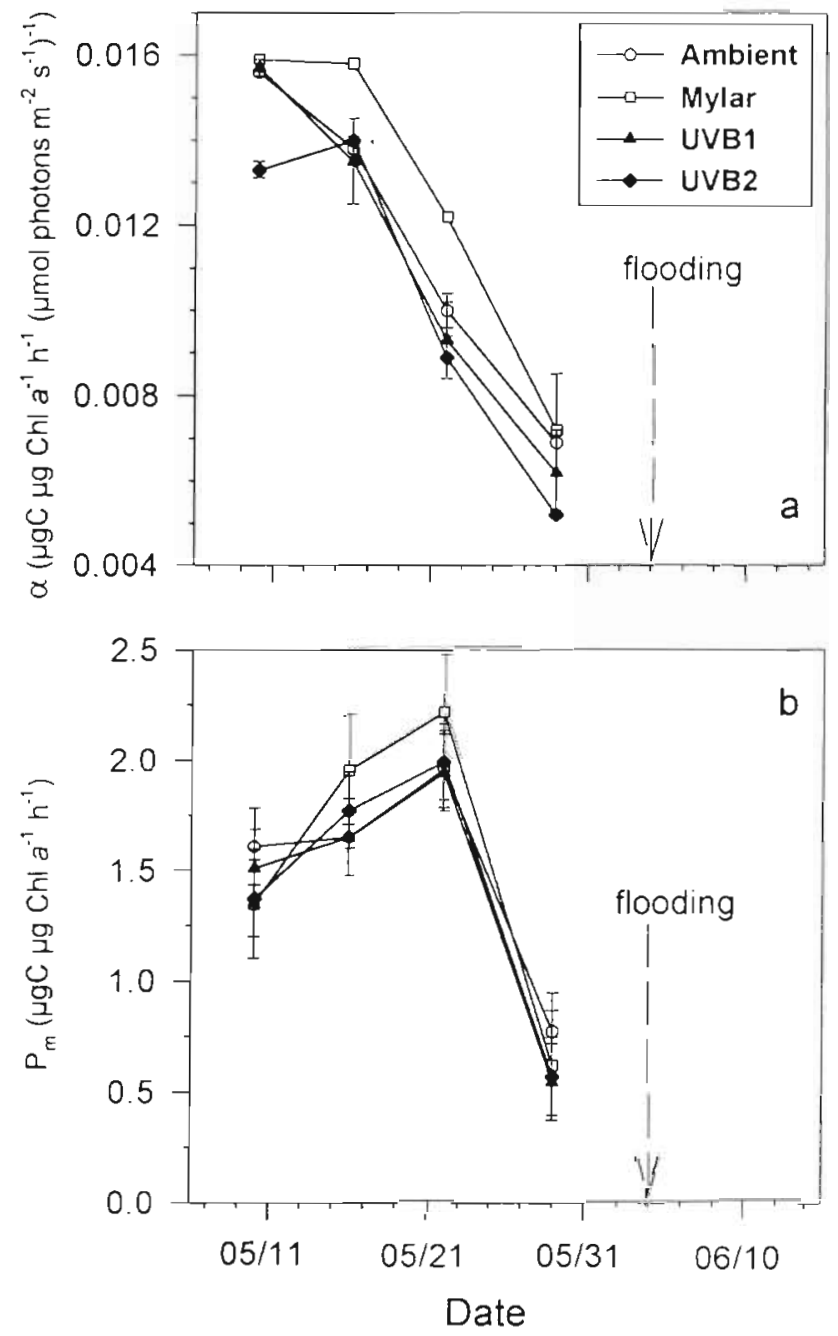

Fig. 6. Changes in the $P$ versus $E$ parameters through time for each enclosure treatment. Error bars represent $\pm 1 \mathrm{SE}$ for duplicates. The Mylar treatruent had no replicate in this part of the experiment. (a) Initial slope of the photo-synthesis-irradiance curve $(\alpha)$, (b) light-saturated photosynthetic rate $\left(P_{\mathrm{m}}\right)$

ent stress may have been a factor contributing to the lack of UVB effect on growth rates in these assays (Behrenfeld et al, 1994). It should be noted that the polystyrene culture flasks used for measuring grazing rates do not transmit UVB wavelengths shorter than $300 \mathrm{~nm}$. Hence, although our protocol was suitable for evaluating the long-term impact of UVB on grazing pressure, it would have underestimated any direct UV effects during the 24 h assay.

Although the intrinsic variability of this enclosure approach limits our capacity to resolve small differences, this type of assay provides a much more realistic test of the ecological effects of UVB than is typically achieved in either laboratory assays or in situ incubations. The enclosures in our study had a low surface to volume ratio to minimize wall effects, and the water column was open to the atmosphere and sediments as in the natural environment, thereby reducing containment artifacts. The bio-optical environment mimicked that of the surrounding lakewater, and the phytoplankton community in the enclosures (chl $a$ and picocyanobacteria) remained similar to that in the lake, giving confidence in the experimental system. Moreover, this approach allowed the effects of UVB to be assessed under realistic conditions over a timescale sufficient for the plankton communities to respond in terms of physiology, abundance and species composition.

The UVB treatments adopted in this experiment were relatively low in terms of unweighted UVB doses, but realistic relative to the projected trends in ozone depletion over the next decade (Frederick 1997). The biological weighting calculations, however, show much higher fluxes, particularly when compared to the natural day-to-day variations in ambient UVB: up to $26 \%$ in UVB1 and $38 \%$ in UVB2 under the lamps at the water interface. These calculations also illustrate the difficulty in achieving realistic UVB enhancements in outdoor experimental treatments: high mean UVB enhancements could easily result in extreme, highly artificial exposures (relative to PAR and UVA; see Prézelin et al. 1994, Quesada et al. 1995). This could have been the case in our study on cloudy days $6 \mathrm{~d}$ with overcast conditions, $10 \mathrm{~d}$ with scattered cloud conditions and $4 \mathrm{~d}$ with clear sky conditions).

An important additional factor to consider for calculating UVB exposures is the attenuating effect of the water column. The CDOM content of the water reduces irradiance and also has marked effects on UV spectral composition with depth. For Jack's Lake, a daily surface weighted UVB enhancement of $3.3 \mathrm{~kJ}$ $\mathrm{m}^{-2}$ at the surface would be reduced to $0.44 \mathrm{~kJ} \mathrm{~m}^{-2}$ at $20 \mathrm{~cm}$ (but still 18\% above ambient at this depth) and to only $0.0003 \mathrm{~kJ} \mathrm{~m}^{-2}$ at the bottom of the enclosed water column. These calculations underscore the critical importance of CDOM in dampening the effects of variation in incident UVB (see Laurion et al. 1997, Vincent et al. 1998). Any photobiological damage caused by UVB exposure will be restricted to organisms that are trapped within the diurnally stratified surface layer for prolonged periods of time, and these populations will be intermittently mixed and diluted with less exposed cells at depth, thereby reducing the long-term net water column effect.

Consistent with the significant Ochromonas sp. response, the photosynthetic data show that the level of screening conferred by CDOM in the Jack's Lake enclosures was not sufficient to completely protect the plankton from UV effects. Under natural and enhanced levels of UVB the phytoplankton became less effective at using light for photosynthesis (reduced $\alpha$ ) 
relative to the minus-UVB treatment. The $P-E$ curves were performed at the same PAR intensities without UVB (the neutral density filters removed the UVB waveband), hence the difference between treatments reflects long-term changes in the ability of cells to use light, and may involve photoregulation rather than photodamage (Henley 1993). This light-harvesting ability decreased in all treatments as the spring progressed. Such changes may reflect the response to increasing incident light as the summer solstice was approached and the gradual decrease in mixing depth with increasingly frequent diurnal stratification; alternatively, this effect may have been a response to increasing temperature (Davidson 1991). The Mylar film also attenuated total sun irradiance by $14 \%$, which might partially explain the delay in the observed decrease in $\alpha$. As the spring progressed, nutrient status and size distribution might also have influenced the community-averaged $\alpha$.

Despite $3 \mathrm{wk}$ of enhanced or ambient incident UVB exposure in this experiment, there was no evidence of deterioration in the phytoplankton community structure or impairment of zooplankton grazing activity relative to the UVB-screened treatment. There was no extinction of particular phytoplankton species or taxonomic groups, nor was there a significant impact on the relative contribution of algal size classes. If community-level shifts did occur, they were small relative to the variability found in this type of experimental system. The study of Bergeron \& Vincent (1997) in a subarctic oligotrophic lake showed for smaller microcosms (20 l) and shorter timescales (6 to 9 d) that, despite high near-surface UVB dosages, the response of the plankton community was small relative to those typically reported in laboratory studies. At these incubation timescales the phytoplankton appear to be able to adjust to changes in incident UVB (Karentz 1994). It is possible that the shallow water column in the littoral zone, or the frequent occurrence of diurnal stratification in this type of environment, might pre-select for species resistant to increasing levels of UVB radiation (Helbling et al. 1992, Halac et al. 1997, Vinebrooke \& Leavitt 1999). Moreover, UV-screening by CDOM in the water column is likely to confer a high level of protection on the overall community. Our results imply that for this type of lake system the responses to increased ozone depletion will be much less severe than those predicted solely on the basis of trends in incident UVB in combination with laboratory-based assay data.

Acknowledgements. The authors thank Linda Toy, Lynne Milford, Shawn Good and Caroline Pagé for their invaluable assistance in the field and laboratory, and 3 anonymous reviewers for their insightful comments and suggestions. This research was funded by the Natural Sciences and Engineering Research Council of Canada, with additional support from
Centre d'études nordiques (Université Laval), and the National Water Research Institute (Environment Canada).

\section{LITERATURE CITED}

Behrenfeld MJ, Chapman JW, Hardy JT, Lee H II (1993) Is there a common response to ultraviolet- $B$ radiation by marine phytoplankton? Mar Ecol Prog Ser 102:59-68

Behrenfeld MJ, Lee H II, Small LF (1994) Interactions between nutritional status and long-term responses to ultraviolet-B radiation stress in a marine diatom. Mar Biol 118:523-530

Bergeron M, Vincent WF (1997) Microbial food web responses to phosphorus supply and solar UV radiation in a subarctic lake. Aquat Microb Ecol 12:239-249

Bothwell ML, Sherbot DMJ, Roberge AC, Daley RJ (1993) Influence of natural ultraviolet radiation on lotic periphytic diatom community growth, biomass accrual, and species composition: short-term versus long-term effects. J Phycol 29:24-35

Bothwell ML, Sherbot DMJ, Pollock CM (1994) Ecosystem response to solar ultraviolet- $B$ radiation: influence of trophic-level interactions. Science 265:97-100

Cullen JJ, Lesser MP (1991) Inhibition of photosynthesis by ultraviolet radiation as a function of dose and dosage rate: results for a marine diatom. Mar Biol 111:183-190

Cullen JJ, Neale PJ, Lesser MP (1992) Biological weighting function for the inhibition of phytoplankton photosynthesis by ultraviolet radiation. Science 258:646-650

Davidson AT, Bramich D, Marchant HJ, McMinn A (1994) Effects of UV-B irradiation on growth and survival of Antarctic marine diatoms. Mar Biol 119:507-515

Davidson AT, Marchant HJ, de la Mare WK (1996) Natural UVB exposure changes the species composition of Antarctic phytoplankton in mixed culture. Aquat Microb Ecol 10: 299-305

Davidson IR (1991) Environmental effects on algal photosynthesis: temperature. J Phycol 27:2-8

El-Sayed SZ, Van Dijken GL, Gonzalez-Rodas G (1996) Effects of ultraviolet radiation on marine ecosystems. Int $J$ Environ Stud 51:199-216

Frederick JE (1997) The climatology of solar UV radiation at the Earth's surface. Photochem Photobiol 65:253-254

Häder DP, Worrest RC (1991) Effects of enhanced solar ultraviolet radiation on aquatic ecosystems. Photochem Photobiol 53:717-725

Häder DP, Worrest RC, Kumar HD, Smith RC (1995) Effects of increased solar ultraviolet radiation on aquatic ecosystems. Ambio 24:174-180

Halac S, Felip M, Camarero L, Sommaruga-Wögrath S, Psenner R, Catalan J, Sommaruga R (1997) An in situ enclosure experiment to test the solar UVB impact on plankton in a high-altitude mountain lake. I. Lack of effect on phytoplankton species composition and growth. J Plankton Res 19:1671-1686

Helbling EW, Villafañe V, Ferrario M, Holm-Hansen O (1992) Impact of natural ultraviolet radiation on rates of photosynthesis and on specific marine phytoplankton species. Mar Ecol Prog Ser 80:89-100

Henley WJ (1993) Measurement and interpretation of photosynthetic light-response curves in algae in the context of photoinhibition and diel changes. J Phycol 29:729-739

Hochberg Y, Tamhane AC (1987) Multiple comparison procedure. Wiley, New York

Holm-Hansen O, Helbling EW, Lubin D (1993) Ultraviolet radiation in Antarctica: inhibition of primary production. Photochem Photobiol 58:567-570 
Jokiel PL, York H (1984) Importance of ultraviolet radiation in photoinhibition of microalgal growth. Limnol Oceanogr 29:192-199

Karentz D (1994) Ultraviolet tolerance mechanisms in Antarctic marine organisms. Ultraviolet radiation in Antarctica: measurements and biological effects. Antarctic Res Ser 62: $93-110$

Karentz D, Cleaver JE, Mitchell DL (1991) Cell survival characteristics and molecular responses of Antarctic phytoplankton to ultraviolet-B radiation. J Phycol 27:326-341

Karentz D, Bothwell ML, Coffin RB, Hanson A, Herndl GJ, Kilham SS, Lesser MP, Lindell M, Moeller RE, Morris DP, Neale PJ, Sanders RW, Weiler CS, Wetzel RG (1994) Impact of UVB radiation on pelagic freshwater ecosystems: report of working group on bacteria and phytoplankton. Arch Hydrobiol Beih 43:31-69

Keller AA, Hargraves P, Jeon $H$, Klein-McPhee $G$, Klos E, Oviatt C, Zhang J (1997a) Effects of ultraviolet-B enhancement on marine trophic levels in a stratified coastal system. Mar Biol 130:277-287

Keller AA, Hargraves P, Jeon $H$, Klein-McPhee $G$, Klos $E$, Oviatt C, Zhang J (1997b) Ultraviolet-B radiation enhancement does not affect marine trophic levels during a winter-spring bloom. Ecoscience 4:129-139

Kerr JB, McElroy CT (1993) Evidence for large upward trends of UV-B radiation linked to ozone depletion. Science 262 $1032-1034$

Kerr JB, McElroy CT, Wardle DI, Olafson RA, Evans WFJ (1985) The automated Brewer spectrophotometer. In: Zerefos CS, Ghazi A (eds) Atmospheric ozone, Proc Quadrennial Ozone Symposium, Halkidiki, Greece, D Reidel Publishing company, Dordrecht, p 396-401

Landry MR, Hassett RP (1982) Estimating the grazing impact of marine microzooplankton. Mar Biol 67:283-288

Laurion I, Vincent WF, Lean DRS (1997) Underwater ultraviolet radiation: development of spectral models for northern high latitude lakes. Photochem Photobiol 65:107-114

Lindell MJ, Granéli W, Tranvik LJ (1995) Enhanced bacterial growth in response to photochemical transformation of dissolved organic matter. Limnol Oceanogr 40:195-199

Lovejoy C, Vincent WF, Frenette JJ, Dodson JJ (1993) Microbial gradients in a turbid estuary: application of a new method for protozoan community analysis. Limnol Oceanogr 38:1295-1303

Neale PJ, Cullen JJ, Davis RF (1997) Inhibition of marine photosynthesis by ultraviolet radiation: variable sensitivity of

Editorial responsibility: William $L i_{i}$

Dartmouth, Nova Scotia, Canada phytoplankton in the Weddell-Scotia Sea during the austral spring. Limnol Oceanogr 43:433-448

Nusch EA (1980) Comparison of different methods for chlorophyll and phaeopigment determination. Arch Hydrobiol Beih 14:14-36

Platt I, Gallegos CL, Harrison WG (1980) Photoinhibition of photosynthesis in natural assemblages of marine phytoplankton. J Mar Res 38:687-701

Prézelin BB, Boucher NP, Smith RC (1994) Marine primary production under the influence of the Antarctic ozone hole: Icecolors '90. Antarct Res Ser 62:159-186

Quesada A, Mouget JL, Vincent WF (1995) Growth of Antarctic cyanobacteria under ultraviolet radiation: UVA counteracts UVB inhibition. J Phycol 31:242-248

Schindler DW, Curtis PJ, Parker BR, Stainton MP (1996a) Consequence of climate warming and lake acidification for UV-B penetration in North American boreal lakes. Nature 379:705-708

Schindler DW, Bayley SE, Parker BR, Beaty KG, Cruikshank DR, Fee EJ, Schindler EU, Stainton MP (1996b) The effects of climatic warming on the properties of boreal lakes and streams at the Experimental Lakes Area, northwestern Ontario. Limnol Oceanogr 41:1004-1017

Vincent WF, Laurion I, Pienitz R (1998) Arctic and Antarctic lakes as optical indicators of global change. In: Budd WF (ed) Antarctica and global change. Ann Glaciol 27 (in press)

Vincent WF, Roy S (1993) Solar UV-B and aquatic primary production: damage, protection and recovery. Environ Rev 1:1-12

Vinebrooke RD, Leavitt PR (1999) Differential responses of littoral communities to ultraviolet radiation in an alpine lake. Ecology 80 (in press)

Wängberg SA Selmer JS, Gustavson K (1996) Effects of UV-B radiation on biomass and composition in marine phytoplankton communities. Sci Mar 60:81-88

Wetzel RG (1993) Humic compounds from wetlands: complexation inactivation, and reactivation of surface-bound and extracellular enzymes. Verh Int Verein Limnol 25:122-128

Williamson CE (1995) What role does UV-B radiation play in freshwater ecosystems? Limnol Oceanogr 40:386-392

Worrest RC, Thomson BE, Van Dyke H (1981) Impact of UV-B radiation upon estuarine microcosms. Photochem Photobiol 33:861-867

Xiong F, Lederer F, Lukavsky J, Nedbal L (1996) Screening of freshwater algae (Chlorophyta, Chromophyta) for ultraviolet-B sensitivity of the photosynthetic apparatus. J Plant Physiol 148:42-48

Submitted: December 19, 1997; Accepted: June 22, 1998 Proofs received from author(s): November 19, 1998 